\title{
Older Women with Younger Men - a new relationship of conspicuous consumption
}

\author{
Di Fan ${ }^{1, a}$ \\ ${ }^{1}$ Faculty of Accounting, Tianfu College of Southwestern University of Finance and Economics, \\ Mianyang, Sichuan Province, China \\ amsfandi@163.com
}

Keywords: May-September romances, Consumption Pattern, Conspicuous Consumption.

\begin{abstract}
This study serves to investigate the topic of May-September romances by means of applying consumer culture theory. Through this approach it is not only possible to understand people's consumption patterns and habits in modern society but also reveals how trends might evolve in the future, thus an ability to forecast possible consumption patterns. By applying theory to practical cases, this study will hence contribute to an increased understanding of how relationship ideals between older women and younger men are shaped through advertising and media representations and its wider societal and cultural ramifications. Furthermore, during previous research concerning relationships between men and women little scholarly attention has been paid to older women dating younger men. Therefore, this study will contribute new and relevant knowledge into an area mainly untapped. Insights and added knowledge in this study area will marketers who want to understand current relationship structures in order to explore new and future consumption patterns..
\end{abstract}

\section{Introduction}

Even science The Graduate (1963) and Harold and Maude (1971), the older women-younger men paradigm has been a topic of cinematic curiosity. In our modern consumer society it can be detected that the relationship structure between men and women has significantly changed to those centuries ago. Underlying this new relationship structure is the increasing trend of older women dating younger men. In the media this movement is also referred to as 'May-September romances' which implies that one partner is significantly older than the other. In our study we shall treat the definition as the female being older (whether it be 5, 10 or 20 years) than the male (Helen, 1975). The relationship between man and woman changed over time from a cultural andhistorical as well as a sociological perspective. It is described how the dominance of the male diminished as the female become more independent during the last centuries, leading us to the relationship construct we can find in our current consumer culture society. One way to express the subordinate role of women is Goffman's concern with power relations between men and women demonstrated in advertising (Corrigan, 2006). He argues that women are usually displayed as being inferior to men, whereas the man inhabits a higher physical place than the woman who is many times displayed lying on the bed or floor (ibid.). As will be described in subsequent chapters, advertising in our current society already reveals how gender roles have changed.

Changes in the relationship between men and women can be also explained by the changing role of women due to their emancipation. One example of the emancipation of women was through the establishment of department stores which offered women a place in the public sphere (Corrigan, 2006). Nowadays, women already belong to the professional managerial class and many are becoming CEOs of highly successful multinational companies, through the increased participation in the labour force, women became more independent and were consequently less dependent on men (Simon \& Landis, 1989).It can be argued that the changing role of the women through the participation in the labour force had an impact on the relationship between men and women(Strow \& Strow, 2006).

Even the relationship between younger women/men and Older men/women has been risen lots of attention in public, the researches on this subject are very limited or outdated. There are only some 
articles which public in periodicals that discuss the impact of age difference on the relationship, the issues that arise for the couple, and any difference in husbands and wives experience in woman-oldermarriages (Nichole, 2006). There are also some researches focuses on family studies (B. Lee, 2010). However, the formal academic analysis on this paradigm relationship still lack and the perspective on the 'May-September romances' can be treated as a model of consumption is still not been explained enough. In this paper the relationship between the elder women and younger men will be interpreted as the start of conspicuous consumption.

In our current consumer society the relationship between men and women seems to have changed to an even more independent and self-centred style and that the traditional role of relationships and marriage has vanished. Women are now choosing relationships that suit their needs, wants and lifestyle preferences. In this research study we shall examine older women dating younger men as a main relationship change agent.

\section{Methodology}

The main source of analysis stems from the secondary sources. The media platforms in which the report will use to specifically analyze the institution's portrayal of May-September romances is movies, TV shows, the internet, tabloid magazines and advertisements. Popular media has been browsed for occurrences of material, whether it is online, print or visual, that in one way or another deal with the topic of older women being with younger men. Therefore the material collected has been examined on a macro level and analyzed in order to find prominent features of how the normalization of May-September romances takes place. This paper has also conducted a content analysis of a tabloid magazine and various advertisements. At the same time this will exemplify the media's growing attention on such relationships and the fact that companies are becoming aware of this trend and thus capitalizing on this new phenomenon in a consumption capacity.

3Younger Men as Conspicuous Consumption

Thorstein Veblen (1899) was on of the first who wrote about conspicuous consumption in his book The Theory of the Leisure Class. He defined conspicuous consumption as the waste of money and/or resources by people to display a higher status than others. Veblen described the consumption as a trickle-down process in that the higher class creates the consumption patterns and values, which are then copied by the lower classes. These consumption patterns lose their attractiveness as soon as they become available to everyone, so consequently the higher class creates new patterns. This process repeats itself constantly (Veblen, 1899).

If we look at celebrity women like Madonna, Demi Moore or Jennifer Aniston, they are all famous and have high financial power to buy typical status symbols such as mansions, expensive and rare cars, and designer fashion. Now however they have younger men as accessories by there side. Can we therefore state that a younger man is a new form of conspicuous consumption? Today we consume to tell the world who we are and where we belong to define our social position. We consume to achieve mental stimulation and to avoid boredom, therefore consumption not only has a material character. This relationship enables the older women to tell the world that she feels good and attractive. She feels younger inside and maybe looks younger externally. With this in mind we can therefore argue that a younger man is a new consumption pattern for older women.

So why not choose a younger man? One could argue that older women's utilisation of the younger man is a new form of conspicuous consumption as most men have their own income and therefore women don't use them to show their social status by spending money on him. Tina Turner, in her early 60s, said that Bach (15 years younger) is a 'good companion', and that their relationship is stress-free, and that it is not an issue that he makes considerably less money than she. She said

'There is no stress because we are both independent,' she says. 'He works; he has his money. I work, and I have my money. He makes contributions to help me as much as he can with the expenses and how I live... I don't worry that he's not a man with money, so to speak. We laugh a lot. He's a typical German who doesn't have a real good sense of humour. I've changed him a lot, and he often thanks me for changing him and making him a better person. It's a good, healthy relationship.' (Ebony, 1998) 
If we explore media's representation of this new consumption patterns, the relationship between an older woman and a younger man is not always portrayed in a positive light. Language such as 'cougar' to

'depict the women as predator, rather than an empowered, independent and loving person is often used'. (CNN.com/living, 2008)

Similarly younger men are portrayed as 'toy boys' for the rich and famous women to play with. In a Vogue Interview Jennifer Aniston said

'I never liked Sex and the City, the kind of thing where women only feel empowered once they find the man. It is just not up my alley. I don't believe in it. There is nothing you can control about love'.(Vogue, December 2008)

Interestingly, men as well find the derogatory terms to describe their position in the relationship offensive. Ashton Kutcher revealed that

"boy toy' just never sat well with me'. (OK!magazine, October 2005)

Trigg (2001) compares Veblen's theory of the Leisure Class with Bourdieu's Distinction: a Social Critique of the Judgement of Taste (1984) on conspicuous consumption. He draws similarities and argues that Bourdieu's writings can be seen as a contemporary response and a potential development with its more flexible framework. Bourdieu emphasizes that consumption is about establishing own superior preferences in order to ascertain and project power. This consumption process leads to social differentiation and self-promotion. He was the first to articulate the term 'cultural capital'. In his view, people with cultural capital have greater forms of knowledge, skills, education, and advantages, which consequently give them a higher social status. He suggests that consumption is more a trickle-round than a trickle-down process

'with upper class tastes drawing at times from popular working class tastes and also transmitting to the less sophisticated middle class', exemplifying the 'status float phenomenon'. (Trigg, 2001:108)

If we examine today's celebrities they are not the only group who have relationships with younger men. There are lower class women who have relationships with younger men and this relationship is not limited to the upper class. Therefore it can be argued that this form of consumption is not just a trickle-down effect, rather a trickle-round. Although the media only portrays celebrities in these relationships, their role is to appropriate and reflect what wider society trends are consuming.

It must be highlighted however that to be in a relationship with a younger man is not just a form of consumption but a new lifestyle. It is a way a person lives with a characteristic, bundle of behaviours, which includes consumption, social relation, entertainment, and dress. It also reflects an individual's attitudes, values or worldview. As a general trend, the 'normal' consumer seeks to emulate those who are above them on the social hierarchy. They imitate celebrities and other icon's tastes, lifestyles, and preferences. Veblen had no explicit consideration about different lifestyles but mentions 'changing styles' and 'schemes of life'.

'Veblen's model looks as these schemes of life vertically, according to the different points on the social ladder' (Trigg, 2001: 113).

Therefore women in a relationship with a younger man reach a new social step in the hierarchy. Bourdieu, a hundred years later, within the concept of cultural capital

'is able to build a theoretical framework in which the lifestyles of different social groups can be understood in relation to the social hierarchy. Lifestyles do not relate only to vertical points in the class hierarchy, but also cut across the social hierarchy horizontally'. (Trigg, 2001:110)

Consequently female celebrities such as Demi Moore or Tina Turner are at the same social position than before their relationship however have just changed their lifestyle.

\section{Conclusion}

By drawing upon relevant consumer culture theories as a foundation for the discussion on May-September romances, one can make a number of conclusions about this relationship dynamic and how it is affected or is affecting social and cultural behaviours of individuals, as well institutions.

Firstly, it can be said that this trend is exemplary of a trickle-round rather than a trickle-down effect. Although the media focuses its attention on older women celebrities in relationships with 
younger men we cannot be limited in thinking that the rest of society, whether it be lower or middle class women, are not performing such acts as well and were in fact the first to practice this behaviour. These women, by adopting this 'lifestyle' are cutting through vertical and horizontal points of the social hierarchy. Secondly, we found that women are using younger men as possessions and a mode of self-extension. The younger male is a vehicle in which a women can express herself, however as we found by examining a variety of media channels, the woman's utilisation of the man as an object is multi-layered. On the one hand a woman may seek to use a younger man purely to feel young and fulfil physical desires, whilst others may actually seek companionship, spiritual extension and a genuine relationship. Ultimately, the media (such as TV, movies and the internet) as well as capitalist institutions (such as advertising and marketing firms) have normalised, the once frowned upon, May-September romance. Media's portrayal of the older woman however is somewhat skewed as for the majority of instances she is represented as a women of power, independence, career-orientated and from the upper class. This could be argued is reflective of the context in which the media is portraying the character e.g the US sitcom 'Lipstick Jungle' is set in upper-class Manhattan or the glamorous Hollywood setting of Samantha Jones in Sex and the City Movie. As previously mentioned this is the media's way of glamorizing the new phenomenon and linking top entertainers, television, movie stars and women of power having relationships with younger men. As a consequence this facilitates the normalisation process as the mass public hold what celebrities do in their private life as a basis of emulation as well as their fictitious characters in TV or movie roles. We can predict that as 'May-September' romances become more widely spread across society, advertisers and marketers will take advantage of and capitalise on this trend by commercialising this relationship to sell more goods.

\section{References}

[1] Bateson, G., (1982), Difference, Double Description and the Interactive Designation of Self'Studies in Symbolism and Cultural Communication, ed. F. Allan Hanson, Manhattan, KS: University of Kansas Publications in Anthropology, 3-8

[2] Belk, R., (1988), Possessions and the Extended Self, The Journal of Consumer Research, Vol 15. No. 2 September, 139-168

[3] Corrigan, P., (1997), Sociology of Consumption, London , SAGE Publications

Holt, D. B., (1998), Does Culture Capital Structure American Consumption?Journal of Consumer Research, 6, 14

[4] Goldman, R., (1992), Reading Ads Socially' in Corrigan, P., (1997), Sociology of Consumption, London, SAGE Publications

[5] Kates, D. and Varzos, N., (1987), Aspects of the Priapic Theory of Gun Ownership, paper presented at the 1987 Popular Culture Association Meetings, Montreal, Quebec, Canada

[6] McDonald, I., (2004), Women in management: an historical perspective, Employee Relations, 26(3): 307-319.

[7] McRobbie, A., (2008), Young Women and Consumer Culture, Cultural Studies, 22:5,531 — 550

[8] Simon, R., Landis, J., (1989), Women's and Men's Attitudes About A Woman's Place and Role. Public Opinion Quarterly, 53: 265-276

[9] Strow, C.W., Strow, B.K., (2006), A history of divorce and remarriage in the United States, Humanomics, 22(4): 239-257

[10] Trigg, A. B., (2001), Veblen, Bourdieu, and Conspicuous Consumption, Journal of Economic Issue, 35(1): 99-115Veblen, T., (1899), The Theory of the Leisure Class, American Journal of Sociology, University of Chicago Press, 5(6): 829-837 